\title{
Evaluasi Penentuan Waktu Tanam Padi (Oriza Sativa L.) Berdasarkan Analisa Curah Hujan Dan Ketersediaan Air Pada Wilayah Bedungan Sekka-Sekka Kabupaten Polewali Mandar
}

\author{
Harli A. Karim ${ }^{1}$, Mardjani Aliyah ${ }^{2}$ \\ Program Studi Agroteknologi Fakultas Ilmu Pertanian Universitas Al Asyariah Mandar \\ harlipertanian@gmail.com
}

\begin{abstract}
Abstrak
Tanaman padi merupakan tanaman penting dan strategis di Indonesia. Kebutuhan pangan khususnya beras mengalami peningkatan setiap tahunnya. Salah satu unsur iklim yang sangat mempengaruhi pertumbuhan dan produksi padi adalah curah hujan. Produktivitas rata-rata tanaman padi berkisar 5,14 t /ha. Padahal, potensi produktivitas tanaman padi dapat mencapai 10-11 t/ha. Salah satu penyebabkan rendahnya produktivitas tersebut adalah ketersediaan air khususnya pada musim kemarau. Upaya yang bisa diakukan untuk mengatasi permasalahan tersebut adalah dengan mengevaluasi dari optimasi waktu tanam berdasarkan analisa curah hujan dan ketersediaan air. Metode yang digunakan adalah metode survei dengan sumber data primer dan data sekunder. Data primer diperoleh dari observasi langsung di lapangan tentang kegiatan dan penerapan teknik budidaya hingga waktu panen dan pasca panen. Data primer juga diperoleh dari suatu pengukuran curah hujan, tanah, hidrotopografi dan teknis jaringan. Data sekunder diperoleh dari penelusuran kepustakaan berupa buku-buku teks, laporan penelitian, jurnal ilmiah, peta serta internet. Penelitian ini bertujuan untuk mengevaluasi waktu tanam padi berdasarkan analisa curah hujan dan ketersediaan air pada Bendungan Sekka-Sekka Kabupaten Polewali Mandar. Hasil penelitian Bendungan Sekka-sekka terbagi menjadi 2 jaringan primer yakni Saluran Induk Maloso Kanan dan Saluran Induk Maloso Kiri. Pembagian air di dilakukan berdasarkan 3 UPTD yakni UPTD Bendung Sekka-Sekka, UPTD Maloso Kanan dan UPTD Maloso Kiri. Penentuan waktu tanam di Wilayah Bendungan Sekka Musim tanam I dimulai pada Bulan Maret dan Bulan April sedangkan pada musim II dimulai pada Bulan Juli , Agustus dan September.
\end{abstract}

Keywords : padi, waktu tanam, curah hujan, sekka-sekka

\section{Pendahuluan}

Tanaman padi merupakan tanaman penting dan strategis di Indonesia. Peningkatan produksi padi nasional menjadi pilihan yang harus dilakukan. Kebutuhan Produksi beras belum mampu memenuhi kebutuhan beras dalam negeri sehingga bertahun-tahun Indonesia menjadi negara pengimpor beras.

Produksi padi tahun 2015 sebanyak 75,55 juta ton Gabah Kering Giling (GKG). Mengalami peningkatan dibandingkan tahun 2014 (Dirjen Tanaman Pangan, 2016). Namun, peningkatan produksi tersebut lebih banyak ditentukan adanya percetakan sawah baru. Bukan peningkatan produktivitas lahan. Produktivitas rata-rata tanaman padi berkisar 5,14 t /ha. Padahal, potensi produktivitas tanaman padi dapat mencapai 1011 t/ha. Salah satu penyebabkan rendahnya produktivitas tersebut adalah ketersediaan air khususnya pada musim kemarau. Padi merupakan tanaman yang memerlukan banyak air dan sangat peka tehadap kekeringan. Salah satu unsur iklim yang sangat mempengaruhi pertumbuhan dan produksi padi adalah curah hujan. Curah hujan akan menentukan ketersediaan dan kecukupan air selama fase pertumbuhan tanaman padi.

Ketersediaan dan kecukupan air akan menentukan pola dan waktu tanam. Waktu tanam yang tidak tepat akan menyebabkan kukurangan air pada saat dibutuhkan dan kelebihan air pada saat tanaman tidak lagi memerlukan air. Upaya penentuan waktu tanaman mengalami permasalahan. Kegagalan panen sering terjadi yang disebabkan waktu tanam yang tidak tepat. Jumlah curah hujan dan ketersediaan air tidak memenuhi jumlah air yang dibutuhkan tanaman. Untuk memenuhi kebutuhan air bagi tanaman, penentuan waktu tanam merupakan hal yang perlu dipertimbangkan.

Untuk mengatasi kekurangan air tersebut terutama di saat musim kemarau diperlukan suatu upaya pengaturan waktu tanam yang sesuai dengan kondisi debit yang ada, sehingga di harapkan dapat diperoleh hasil produksi yang meningkat dari kondisi sebelumnya. Upaya tersebut adalah dengan melakukan evaluasi dan optimasi waktu tanam berdasarkan analisa curah hujan dan ketersediaan air.

Pemanfaatan air sungai secara optimal untuk menunjang kegiatan di bidang pertanian salah satunya adalah dengan mendirikan bangunan air yang fungsinya untuk mengalirkan atau menyuplai air untuk kebutuhan irigasi di persawahan yaitu bangunan bendung. Dalam merencanakan besarnya debit kebutuhan air yang diperlukan pada areal persawahan secara keseluruhan perlu dilakukan suatu analisa kebutuhan air mulai dari saluran pembawa yaitu saluran primer, saluran sekunder dan saluran tersier hingga besarnya kebutuhan di petakpetak sawah, dalam hal ini perlu didukung dengan kelengkapan data-data yang terkait dalam analisa ini untuk mendapatkan hasil yang optimal. 


\section{Metodologi}

Metode yang digunakan adalah metode survei dengan sumber data primer dan data sekunder. Data primer diperoleh dari observasi langsung di lapangan tentang kegiatan dan penerapan teknik budidaya. Data primer juga diperoleh dari suatu pengukuran curah hujan, tanah, hidrotopografi dan teknis jaringan. Data sekunder diperoleh dari Dinas Perkebunan dan Kehutanan, Dinas Pertanian dan Peternakan Kabupaten Polewali Mandar, UPTD Bendungan Sekka-Sekka, Biro Pusat Statistik (BPS), Badan Metereologi dan Geofisika dan lembaga terkait yang berhubungan dengan penelitian. peta serta internet.

\section{Hasil}

\section{Kondisi Umum Bendungan Sekka-Sekka}

Kabupaten Polewali Mandar merupakan salah satu lumbung pangan di Provinsi Sulawesi Barat. Luas lahan keseluruhan mencapai 22.000 ha. Bendungan Sekka-sekka terbagi menjadi 2 jaringan primer yakni Saluran Induk Maloso Kanan dan Saluran Induk Maloso Kiri. Saluran Primer Maloso Kanan mengairi 3.509 ha dan Saluran Primer mengairi 9.076 ha.

Data luasan dan pembagian wilayah Bendungan Sekka-Sekka disajikan pada pada Tabel 1 .

Tabel 1. Luasan dan Pembagian Wilayah Bendungan Sekka-Sekka

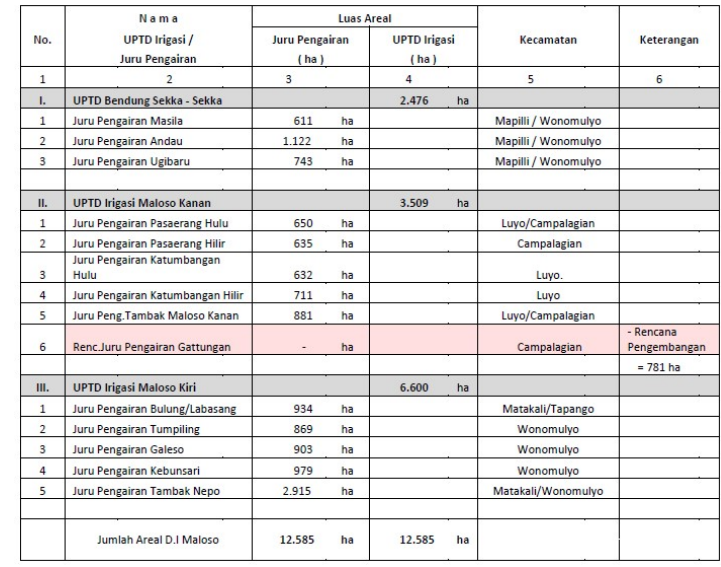

Sumber : UPTD Bendung Sekka-Sekka, 2018

Berdasarkan Tabel 2 menunjukan bahwa Bendungan Sekka-sekka mengairi persawahan yang berada pada 6 Kecamatan yaitu Kecamatan Luyo, Campalagian, Mapilli, Wonomulyo, Tapango dan Matakali. Luas keseluruhan adalah 12.585 ha. Pembagian air di dilakukan berdasarkan 3 UPTD yakni UPTD Bendung Sekka-Sekka, UPTD Maloso Kanan dan UPTD Maloso Kiri. UPTD membawahi 14 Juru Pengairan.

\section{Analisa Curah Hujan}

Curah hujan pada wilayah Bendungan Sekka-Sekka memiliki pola yang hampir sama dengan curah hujan pada Kabupaten Polewali Mandar keselurahan. Curah hujan sangat menentukan pertumbuahan dan produksi tanaman padi. Kabupaten Polewali Mandar terdapat dua musim yaitu musim hujan terjadi pada Oktober sampai Maret dengan curah hujan rata-rata $1750 \mathrm{~mm}$ - 2000 $\mathrm{mm} /$ tahun, sedangkan musim kemarau terjadi pada bulan April sampai September.

Tabel 2. Data Curah Hujan 10 Tahun Terakhir (20052014) di Kabupaten Polewali Mandar

\begin{tabular}{|c|c|c|c|c|c|c|c|c|c|c|c|}
\hline \multirow{2}{*}{ Bulan } & \multicolumn{10}{|c|}{ Tahun } & \multirow{2}{*}{$\begin{array}{l}\text { Rata- } \\
\text { rata }\end{array}$} \\
\hline & 2005 & 2006 & 2007 & 2008 & 2009 & 2010 & 2011 & 2012 & 2013 & 2014 & \\
\hline Januari & 32 & 135 & 58 & 74 & 179 & 204 & 33 & 99 & 112 & 166 & 109 \\
\hline Februari & 133 & 106 & 110 & 122 & 108 & 397 & 40 & 252 & 178 & 20 & 146 \\
\hline Maret & 197 & 85 & 94 & 131 & 88 & 154 & 154 & 194 & 136 & 85 & 131 \\
\hline April & 107 & 131 & 541 & 140 & 363 & 147 & 189 & 221 & 221 & 175 & 223 \\
\hline Mei & 80 & 131 & 429 & 242 & 274 & 356 & 193 & 185 & 233 & 217 & 234 \\
\hline Juni & 69 & 238 & 305 & 211 & 99 & 606 & 35 & 114 & 119 & 191 & 198 \\
\hline Juli & 241 & 124 & 37 & 37 & 229 & 259 & 19 & 158 & 258 & 78 & 144 \\
\hline Agustus & 47 & 0 & 26 & 44 & 27 & 187 & 52 & 42 & 79 & 29 & 53 \\
\hline September & 92 & 9 & 177 & 181 & 144 & 305 & 56 & 105 & 162 & 49 & 128 \\
\hline Oktober & 477 & 37 & 77 & 192 & 197 & 79 & 192 & 196 & 195 & 39 & 168 \\
\hline November & 349 & 155 & 233 & 171 & 272 & 209 & 279 & 204 & 177 & 182 & 223 \\
\hline Desember & 255 & 187 & 274 & 266 & 13 & 0 & 304 & 290 & 214 & 242 & 204 \\
\hline Total & 2079 & 1338 & 2361 & 1811 & 1993 & 2903 & 1546 & 2060 & 2084 & 1473 & 1964 \\
\hline
\end{tabular}

Berdasarkan Tabel 2 Rata-rata jumlah curah hujan tertinggi dimulai Bulan Maret- Juni dan OktoberDesember. Rata-rata curah hujan terendah diperoleh pada Bulan Agustus- September dan Januari-Maret. Pola curah hujan Kabupaten Polewali Mandar pada umumnya menyerupai pola curah hujan pada kedua Saluran Induk Bedungan Sekka-Sekka. Data curah hujan pada Saluran Induk Maloso Kiri disajikan pada Tabel 3.

Tabel 3. Data Curah Hujan di Kecamatan Mapilli (Saluran Induk Maloso Kiri) 5 Tahun Terakhir (2013-2017)

\begin{tabular}{|c|c|c|c|c|c|c|c|}
\hline \multirow{2}{*}{ No } & Bulan & 2013 & 2014 & 2015 & 2016 & 2017 & \multirow{2}{*}{$\begin{array}{c}\text { Rata- } \\
\text { Rata }\end{array}$} \\
\cline { 2 - 7 } & Tahum & Jml mm & Jml mm & Jml mm & Jml mm & Jml mm & \\
\hline 1 & Januari & 90 & 205 & 146 & 179 & 145 & 135 \\
\hline 2 & Februari & 134 & 15 & 82 & 175 & 82 & 71 \\
\hline 3 & Maret & 139 & 75 & 109 & 294 & 155 & 127 \\
\hline 4 & April & 180 & 182 & 234 & 357 & 13 & 157 \\
\hline 5 & Mei & 226 & 200 & 95 & 262 & 183 & 148 \\
\hline 6 & Juni & 76 & 195 & 316 & 138 & 260 & 189 \\
\hline 7 & Juli & 183 & 78 & 0 & 120 & 181 & 76 \\
\hline 8 & Agustus & 26 & 51 & 8 & 20 & 24 & 21 \\
\hline 9 & September & 66 & 116 & 0 & 71 & 72 & 59 \\
\hline 10 & Oltober & 168 & 35 & 147 & 154 & 315 & 130 \\
\hline 11 & November & 119 & 35 & 147 & 154 & 315 & 130 \\
\hline 12 & Desember & 231 & 106 & 192 & 76 & 175 & 109 \\
\hline
\end{tabular}

Sumber : BPP Kecamatan Mapilli, 2018

Berdasarkan Tabel 3 memperlihatkan bahwa rata-rata hujan tertinggi pada wilayah Saluran Induk Maloso Kiri dimulai pada bulan Maret-Juni dan OktoberDesember. Rata-rata hujan terendah diperoleh pada Bulan Juli-September dan Februari-April. Saluran Induk Maloso Kanan meliputi 2 Kecamatan yaitu Mapilli, Wonomulyo, Matakali dan Tapango dengan luas sawah $9.076 \mathrm{Ha}$. 
Tabel 4. Data Curah Hujan di Kecamatan Campalgian (Saluran Induk Maloso Kanan) 5 Tahun Terakhir (2013-2017)

\begin{tabular}{|c|c|c|c|c|c|c|c|}
\hline \multirow{2}{*}{ No } & $\begin{array}{l}\text { Bulan } \\
\end{array}$ & 2013 & 2014 & 2015 & 2016 & 2017 & \multirow{2}{*}{$\begin{array}{l}\text { Rata- } \\
\text { Rata }\end{array}$} \\
\hline & Tahun & $\mathrm{Jml} \mathrm{mm}$ & $\mathrm{Jml} \mathrm{mm}$ & $\mathrm{Jml} \mathrm{mm}$ & $\mathrm{Jml} \mathrm{mm}$ & $\mathrm{Jml} \mathrm{mm}$ & \\
\hline 1 & Januari & 140 & 419 & 131 & 141 & 145 & 206 \\
\hline 2 & Februari & 76 & 270 & 98 & 53 & 152 & 244 \\
\hline 3 & Maret & 185 & 71 & 98 & 75 & 151 & 195 \\
\hline 4 & April & 126 & 60 & 132 & 215 & 254 & 289 \\
\hline 5 & Mei & 120 & 538 & 254 & 131 & 34 & 409 \\
\hline 6 & Juni & 17 & 1379 & 34 & 111 & 263 & 718 \\
\hline 7 & $\begin{array}{l}\text { Juli } \\
\end{array}$ & 10 & 541 & 198 & 71 & - & 326 \\
\hline 8 & Agustus & 0 & 499 & 38 & 10 & . & 219 \\
\hline 9 & September & 39 & 64.5 & 118 & 51 & - & 75 \\
\hline 10 & Oltober & 153 & 162 & 131 & 28 & 33 & 172 \\
\hline 11 & November & 190 & 315 & 128 & 169 & 66 & 309 \\
\hline 12 & Desember & 180 & 205 & 189 & 154 & 120 & 303 \\
\hline
\end{tabular}

Sumber : BPP Kecamatan Campalagian, 2018

Berdasarkan Tabel 4 memperlihatkan bahwa rata-rata hujan tertinggi pada wilayah Saluran Induk Maloso Kiri dimulai pada bulan April-Juni dan November-Februari. Rata-rata hujan terendah diperoleh pada Bulan Agustus-Oktober dan Maret. Saluran Induk Maloso Kanan meliputi 2 Kecamatan yaitu Luyo dan Campalagian dengan luas sawah 3.509 Ha.

\section{Analisis Klimatologi}

Berdasarkan data curah hujan selama 10 tahun terakhir (Tabel 1) dapat diketahui rata-rata Bulan Kering (BK) dan Bulan Basah (BB). Menurut Klasifikasi Mohr Jumlah Bulan Kering ditentukan jika curah hujan $<60$ $\mathrm{mm}$ dan Bulan Basah jika curah hujan $>100 \mathrm{~mm}$. Data tersebut dapat digunakan untuk mengetahui klasifikasi iklim di Kabupaten Polewali Mandar.

Tabel 5. Jumlah Bulan Kering dan Basah Kabupaten Polewali Mandar Periode 2005-2014

\begin{tabular}{ccccccccccccc}
\hline \multicolumn{10}{c}{ T a h u n } \\
\hline $\begin{array}{c}\text { Tipe } \\
\text { Bulan }\end{array}$ & 2005 & 2006 & 2007 & 2008 & 2009 & 2010 & 2011 & 2012 & 2013 & 2014 \\
\hline BK & 7 & 9 & 6 & 6 & 6 & 3 & 6 & 4 & 4 & 6 \\
\hline BB & 5 & 3 & 6 & 6 & 6 & 9 & 6 & 8 & 8 & 6
\end{tabular}

Sumber : Data Sudah Diolah, 2018

Tabel 6. Golongan/Tipe iklim menurut Mohr

\begin{tabular}{|c|c|c|}
\hline \multirow{2}{*}{$\begin{array}{c}\text { Golongan/tipe } \\
\text { iklim }\end{array}$} & \multicolumn{2}{|c|}{ Jumlah Bulan } \\
\cline { 2 - 3 } & Bulan Kering (BK) & Bulan Basah (BB) \\
\hline Ia & 0 & 12 \\
\hline Ib & 0 & $6-11$ \\
\hline II & $1-2$ & $4-11$ \\
\hline III & $2-4$ & $4-9$ \\
\hline IV & $4-6$ & $4-7$ \\
\hline V & $6-8$ & $2-5$ \\
\hline
\end{tabular}

Berdasarkan Tabel 5 dan 6 diketahui Wilayah Bendungan Sekka-Sekka Kabupaten Polewali Mandar

Agrovital | Jurnal Ilmu Pertanian Universitas Al Asyariah menurut Klasifikasi Mohr termasuk golangan/tipe iklim IV. Setiap usaha pertanian mempunyai keterkaitan langsung dengan faktor iklim. Faktor iklim sangat besar pengaruhnya terhadap pertumbuhan, produksi dan produktivitas suatu tanaman. Faktor iklim juga menentukan teknik budidaya yang digunakan pada daerah tersebut. Bendungan Sekka-sekka terbagi menjadi 2 jaringan primer yakni Saluran Induk Maloso Kanan dan Saluran Induk Maloso Kiri. Pembagian air di dilakukan berdasarkan 3 UPTD yakni UPTD Bendung Sekka-Sekka, UPTD Maloso Kanan dan UPTD Maloso Kiri. Penentuan waktu tanam di Wilayah Bendungan Sekka Musim tanam I dimulai pada Bulan Maret dan Bulan April sedangkan pada musim II dimulai pada Bulan Juli , Agustus dan September.

Perhitungan Klasifikasi Iklim menurut ScmidhtFerguson juga menggunakan jumlah Bulan Kering (BK) dan jumlah Bulan Basah (BB) namun, dalam menentukan klasifikasi iklim Scmidht-Ferguson menggunakan nilai $\mathrm{Q}$ perbandingan jumlah $\mathrm{BK}$ dengan BK

$\mathrm{Q}=\frac{\text { Jumlah Bulan Kering }}{\text { Jumlah Bulan Basah }} \times 100 \%$

Berdasarkan nilai Q tersebut maka Klasifikasi Iklim Scmidht-Ferguson menetapkan 8 tipe iklim

Tabel 6. Delapan tipe Klasifikasi Iklim menurut Scmidht- Ferguson

\begin{tabular}{|c|l|l|}
\hline Tipe & Nilai Q & Tipe Hujan \\
\hline A & $0 \leq \mathrm{Q}<14,3$ & Sangat basah \\
\hline B & $14,3 \leq \mathrm{Q}<33,3$ & Basah \\
\hline C & $33,3 \leq \mathrm{Q}<60,0$ & Agak basah \\
\hline D & $60,0 \leq \mathrm{Q}<100$ & Sedang \\
\hline E & $100 \leq \mathrm{Q}<167$ & Agak kering \\
\hline F & $167 \leq \mathrm{Q}<300$ & Kering \\
\hline G & $300 \leq \mathrm{Q}<700$ & Sangat kering \\
\hline H & $700 \leq \mathrm{Q}$ & Luar biasa kering \\
\hline
\end{tabular}

Berdasarkan nilan $Q=5 / 6 \times 100 \%=83 \%$, maka Kabupaten Polewali Mandar menurut Scmidht-Ferguson bertipe iklim D

\section{Kebutuhan air irigasi}

Berdasarkan perhitungan kebutuhan air irigasi yang telah disingkronkan dengan data observasi dan perhitungan langsung di lokasi penelitian. Kebutuhan air irigasi disesuaikan dengan fase petumbuhan tanaman padi. Berdasarkan Tabel 1, wilayah Bendungan SekkaSekka memiliki 2 saluran induk yaitu Saluran Induk Maloso Kanan dan Saluran Induk Maloso Kiri. Maloso Kanan mengairi persawahan seluas 3.500 ha dan Maloso Kiri 9076 ha. Wilayah Bendungan Sekka-Sekka 
merupakan salah satu pusat produksi padi di Polewali Mandar. Salah satu cara untuk mengatasi kondisi diatas maka perlu diketahui kebutuhan air irigasi daerah irigasi ini dengan tepat sehingga kebutuhan air irigasi bagi tanaman padi dapat terpenuhi. Kebutuhan air padi sawah meliputi kebutuhan air untuk penyiapan lahan, kebutuan air untuk pertumbuhan tanaman (evapotranspirasi), kebutuhan air untuk perkolasi (rembesan) dan kebutuhan air untuk pengganti lapisan air.

\section{Penentuan Waktu Tanam}

Berdasarkan analisis iklim, jenis tanah, topografi dan hidrotopografi, kebutuhan air irigasi dan ketersediaannya, maka ditentukan waktu tanam yang memungkinkan untuk diterapkan di daerah studi. Berdasarkan pertimbangan ketersediaan air hujan, penanaman padi di Kabupaten Polewali Mandar dapat dilakukan pada bulan April untuk Periode I dan bulan Oktober untuk Periode II. Salah satu pertimbangannya adalah pada bulan tersebut masih tersedianya air hujan untuk pertumbuhan awal tanaman padi.

Tabel 7. Periode Musim dan Curah Hujan rata-rata per musim (2005-2014) di Kabupaten Polewali Mandar

\begin{tabular}{|c|c|c|c|c|c|c|}
\hline \multirow[b]{2}{*}{ Periode } & \multicolumn{3}{|c|}{ Musim Hujan } & \multicolumn{3}{|c|}{ Musim Kemarau } \\
\hline & Periode I & Periode II & $\begin{array}{l}\text { Curah } \\
\text { Hujan } \\
(\mathrm{mm})\end{array}$ & Periode I & Periode II & $\begin{array}{l}\text { Curah } \\
\text { Hujan } \\
\text { (mm) }\end{array}$ \\
\hline Bulan & April-Juli & $\begin{array}{l}\text { Oktober- } \\
\text { Desember }\end{array}$ & 208 & $\begin{array}{c}\text { Januari- } \\
\text { Maret }\end{array}$ & $\begin{array}{c}\text { Juli- } \\
\text { September }\end{array}$ & 118,5 \\
\hline
\end{tabular}

Sumber : Data Sekunder Setelah Diolah, 2018

Berdasarkan data rata-rata curah hujan 10 tahun periode 2005-2014, di daerah Kabupaten Polewali Mandar musim hujan berlangsung selama 6 bulan dari bulan Oktober hingga Desember dan musim hujan kedua dimulai April hingga Juni, dengan jumlah curah hujan rata-rata sebesar $208 \mathrm{~mm}$. Musim kemarau berlangsung selama 6 dari bulan Januari hingga Maret dan Juli sampai September, dengan jumlah curah hujan sebesar 118,5 $\mathrm{mm}$

Tabel 7 menerangkan bahwa selama enam bulan curah hujan relatif tinggi dan enam bulan berikutnya rendah.Kriteria musim hujan dan musim kemarau ditentukan berdasarkan rata-rata curah hujan selama periode tersebut. Badan Meteorologi Klimatologi dan Geofisika (2011), menetapkan bahwa jika dalam satu bulan terjadi curah hujan di atas $150 \mathrm{~mm}$ maka daerah tersebut mengalami musim hujan, sebaliknya jika dalam satu bulan curah hujan kurang dari $150 \mathrm{~mm}$ maka daerah tersebut mengalami musim kemarau. Penyesuaian waktu tanam dengan periode musim karena dapat menurunkan resiko penurunan produksi hasil tanaman pertanian. Berdasarkan Tabel 7 dapat ditentukan waktu tanam yang tepat untuk penanaman awal tanaman padi. Penentuan waktu tanam harus mempertimbangkan dan menyesuaikan dengan periode musim yang terjadi.

Berdasarkan pertimbangan ketersediaan air hujan, penanaman padi di Bendungan Sekka-Sekka dapat dilakukan pada bulan April dan bulan Agustus. Salah satu pertimbangannya adalah pada bulan tersebut masih tersedianya air hujan untuk pertumbuhan awal tanaman padi Selanjutnya pada fase pertumbuhan vegetatif kebutuhan air diperoleh dari air irigas dan air hujan yang masih ada. Penentuan waktu tanam pada wilayah Bedungan Sekka-Sekka disajikan pada Gambar 1.

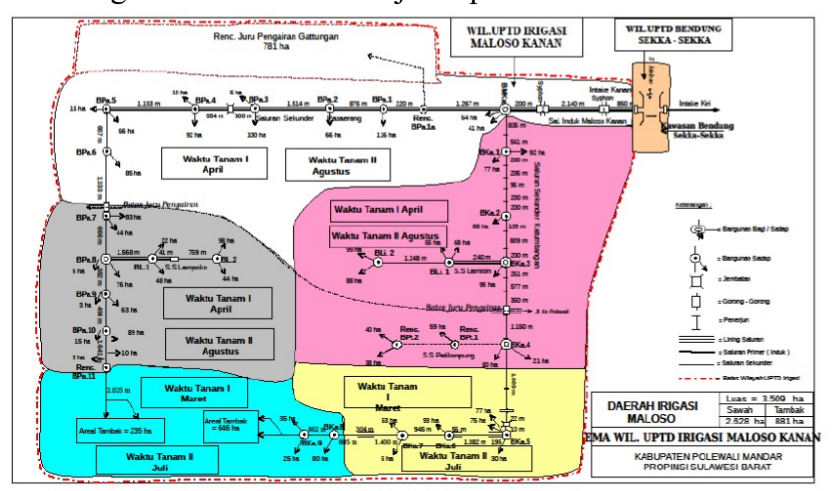

Gambar 1. Penentuan Waktu Tanam Padi Berdasarkan Analisa Curah Hujan dan Iklim pada Saluran Induk Maloso Kanan Bendungan Sekka-Sekka Kabupaten Polewali Mandar

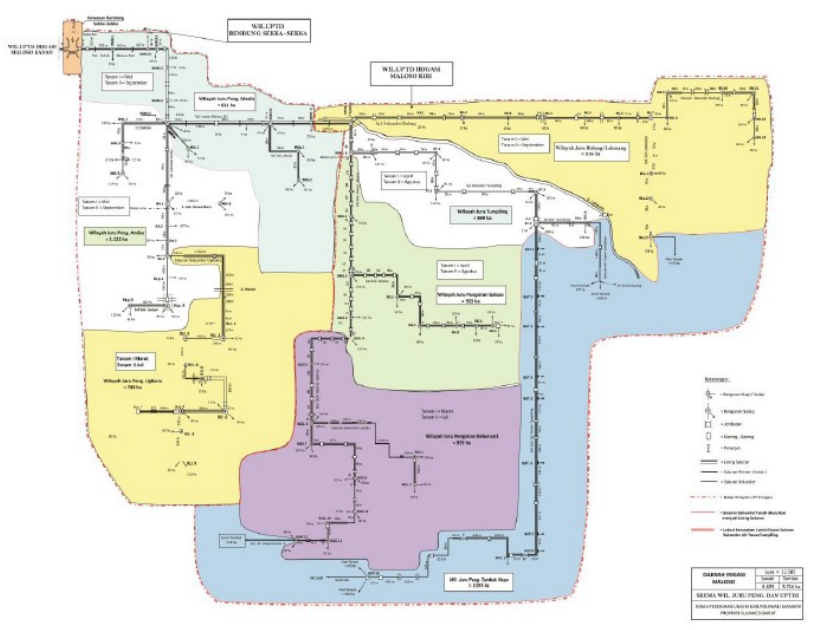

Gambar 2. Penentuan Waktu Tanam Padi Berdasarkan Analisa Curah Hujan dan Iklim pada Saluran Induk Maloso Kiri Bendungan Sekka-Sekka Kabupaten Polewali Mandar

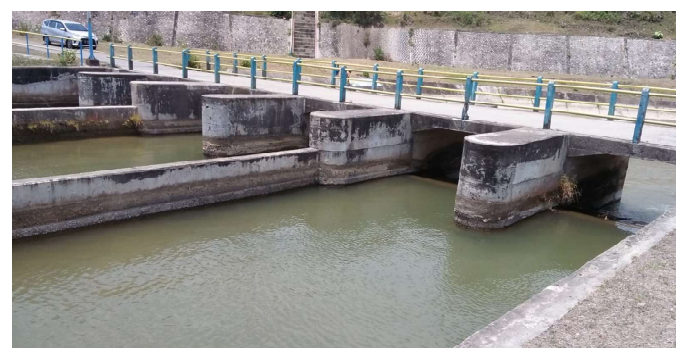

Gambar 3. Salah Satu Saluran Induk Bendungan SekkaSekka 


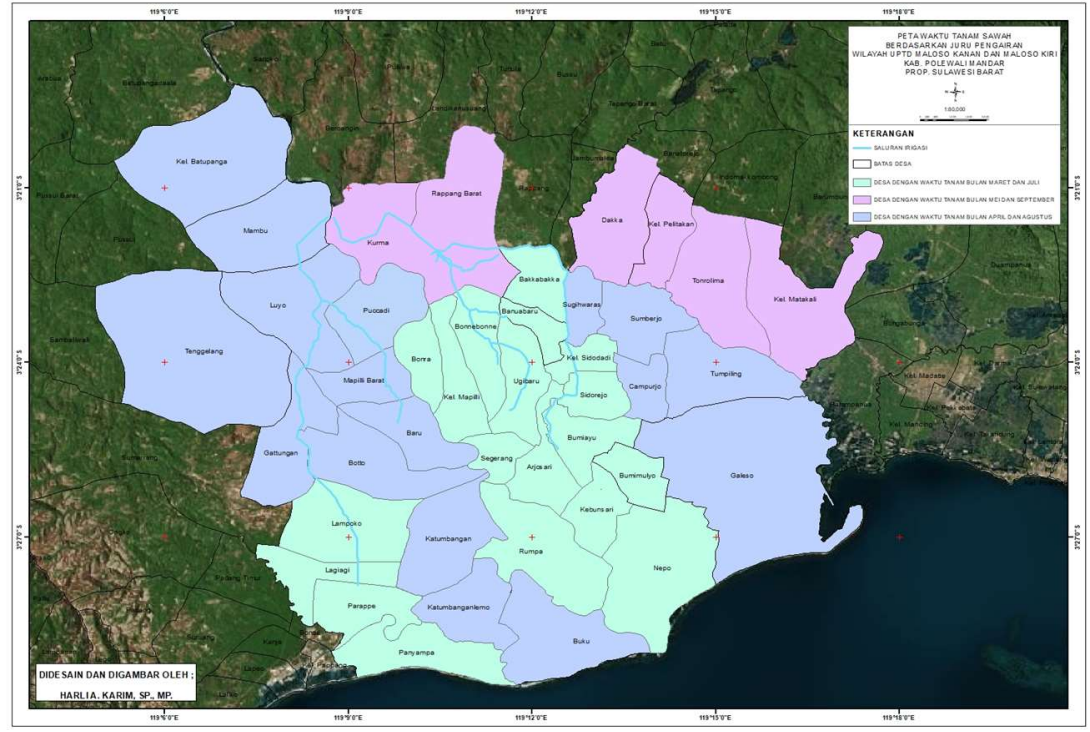

Gambar 4. Waktu Tanam Padi Berdasarkan Desa pada Bendungan Sekka-Sekka Kab. Polewali Mandar

Berdasarkan Gambar 1 dan 2 menunjukan bahwa pertanaman padi dilakukan 2 kali setahun. Periode I dilakukan pada bulan Maret-April dan Periode II dilakukan pada Agustus-September. Penentuan waktu tanam pada setiap juru pengairan didasarkan analisa curah hujan dan ketersediaan air pada bendungan induk. Awal pertanaman pada wilayah Saluran Induk Maloso Kanan yang meliputi Kecamatan Luyo dan Campalagian lebih dahulu dibandingkan dengan Saluran Induk Maloso Kiri.

Gambar 4 menunjukan bahwa terdapat 3 periode tanam yaitu pertanaman I dilakukan pada Bulan Maret, April dan Mei. Sedangkan Pertanaman II dilakukan pada Bulan Juli, Agustus dan September.

\section{Kesimpulan}

Berdasarkan analisa data sementara maka dapat disimpulkan sebagai berikut :

1. Bendungan Sekka-sekka terbagi menjadi 2 jaringan primer yakni Saluran Induk Maloso Kanan dan Saluran Induk Maloso Kiri.

2. Pembagian air di dilakukan berdasarkan 3 UPTD yakni UPTD Bendung Sekka-Sekka, UPTD Maloso Kanan dan UPTD Maloso Kiri

3. Penentuan waktu tanam di Wilayah Bendungan Sekka Musim tanam I dimulai pada Bulan Maret dan Bulan April sedangkan pada musim.

\section{Ucapan Terima Kasih}

Ucapan terima kasih yang paling tulus dan penghargaan kepada Direktorat Riset dan Pengabdian Masyarakat (DRPM) Kementerian Riset, Teknologi dan Perguruan Tinggi (Kemenristekdikti) atas dukungan pada Penelitian ini dan semoga penggunakan fasilitas penelitian tetap akan diberikan di masa yang akan datang

\section{Daftar Pustaka}

Asnawi, R. 2013. Peningkatan Produktivitas dan Pendapatan Petani Melalui Penerapan Model Pengelolaan Tanaman Terpadu Padi Sawah di Kabupaten Pesawaran, Lampung. Jurnal Penelitian Pertanian Terapan Vol. 14 (1):44-52 ISSN $1410-5020$

Balai Besar Penelitian Tanaman Padi. 2016.Info.@litbang.pertanian.go.id. Diakses pada tanggal 20 April 2017

Fadhlullah Ramadhani et. el., 2013. Sistem Teknologi Informasi Kalender Tanam Terpadu. Balai Penelitian Agroklimat dan Hidrologi. Bogor

Pramudia, A., I. Las, H. Syahbuddin, E. Susanti, K.S. Hariyanti, Haryono. 2013. Model Integrasi Prediksi Iklim dan Awal Tanam untuk Mendukung Sistem Informasi Kalender Tanam Terpadu. Laporan Akhir Penelitian. Balai Penelitian Agroklimat dan Hidrologi. Bogor.

Pusat Penelitian dan Pengembangan Tanaman Pangan. 2015. http://www.puslittan.bogor.net/. Diakses pada Tanggal 21 April 2017 
Ruslan Wirosoedarmo,Usman Apriadi, 2015. Studi Perencanaan Pola Tanam Dan Pola Operasi Pintu Air Jaringan Reklamasi Rawa Pulau Rimau Di Kabupaten Musi Banyuasin Sumatera Selatan. Jurnal Teknologi Pertanian Vol.3 No.1: 56 - 66

Runtunuwu, E., H. Syahbuddin, dan W. T. Nugroho. 2011. Deliniasi kalender tanam tanaman padi sawah untuk antisipasi anomali iklim mendukung program peningkatan produksi beras nasional. Majalah Pangan 20(4):341-356.

Runtunuwu, E., H. Syahbuddin, F. Ramadhani, dan W.T. Nugroho. 2012. Dinamika kalender tanam padi di Sulawesi. Submitted to Majalah Pangan. In press.
Sri Maulidani et.al., 2015. Analisis Pola Dan Intensitas Curah Hujan Berdasakan Data Observasi Dan Satelit Tropical Rainfall Measuring Missions (Trmm) 3b42 V7 Di Makassar. Jurnal Sains Dan Pendidikan Fisika (JSPF). UNM Makassar

Woro Estiningtyas, 2015. Asuransi Pertanian Berbasis Indeks Iklim: Opsi Pemberdayaan dan Perlindungan Petani Terhadap Risiko Iklim. Balai Penelitian Agroklimat dan Hidrologi. Jurnal Sumberdaya Lahan Vol. 9 No. 1, Juli 2015; 51-64

Yayan Apriyana, Tigia Eloka Kailaku, 2015. Variabilitas Iklim dan Dinamika Waktu Tanam Padi di Wilayah Pola Hujan Monsunal dan Equatorial. Pros Sem Nas Masy Biodiv Indon 1 (372 2): 366372, April 2015 